19 Revue d'histoire du XIXe siècle

Société d'histoire de la révolution de 1848 et des

révolutions du XIXe siècle

$24 \mid 2002$

Varia

\title{
Où en est l'histoire de l'Europe du XIXe siècle?
}

Histoire et Sociétés, revue européenne d'histoire sociale, $\mathrm{n}^{\circ} 2,2 \mathrm{e}$ trimestre 2002

Louis Hincker

\section{(2) OpenEdition}

Journals

Édition électronique

URL : http://journals.openedition.org/rh19/397

DOI : $10.4000 /$ rh19.397

ISSN : $1777-5329$

Éditeur

La Société de 1848

Édition imprimée

Date de publication : 1 juin 2002

Pagination : 205-207

ISSN : 1265-1354

Référence électronique

Louis Hincker, "Où en est l'histoire de l'Europe du XIXe siècle ? ", Revue d'histoire du XIXe siècle [En ligne], 24 | 2002, mis en ligne le 04 juin 2003, consulté le 22 septembre 2020. URL : http:// journals.openedition.org/rh19/397 ; DOI : https://doi.org/10.4000/rh19.397

Ce document a été généré automatiquement le 22 septembre 2020.

Tous droits réservés 


\section{Où en est l'histoire de l'Europe du XIXe siècle?}

Histoire et Sociétés, revue européenne d'histoire sociale, $n^{\circ} 2$, 2e trimestre 2002

\section{Louis Hincker}

Les "dix-neuviémistes" se comptent, en Allemagne, en Espagne, en Grande-Bretagne en Italie, et en France. Un important numéro de la jeune revue Histoire et Sociétés permet de s'en rendre compte. Les coups de projecteurs portés sur les réflexions historiographiques de nos voisins, trop méconnues, sont ici plus qu'utiles, tellement rares ils n'en sont que plus précieux grâce aussi aux mises au point bibliographiques qu'ils proposent. Bien sûr, toute l'Europe ne pouvait être représentée (regrettons l'absence d'une synthèse sur la Belgique par exemple, et peut-on par ailleurs se passer aujourd'hui du regard américain sur l'histoire de l'Europe du XIX siècle ?), mais cette livraison se veut comme une invitation à ouvrir une réflexion de grande ampleur, et l'on peut se mettre à rêver sur ce que nous apprendraient les débats actuels des historiens en Europe de l'Est, du Nord, ceux des Balkans aussi, sans oublier la Russie, quand ils examinent un XIXe siècle qui semble gagner en spécificité tout en perdant de sa contemporanéité. Car c'est là un des constats non négligeables qui ressort des différents articles de ce numéro d'Histoire et Sociétés. L'altérité du XIX siècle est un nouvel objet d'histoire.

Cela fait une vingtaine d'année qu'un travail de fond a commencé pour reconsidérer un XIX siècle longtemps appréhendé uniquement comme le prolongement de l'Ancien Régime ou comme l'annonciateur du siècle suivant. Une très grande convergence ressort au fil des différentes synthèses qui nous sont données à lire. Et c'est déjà un des leurs grands apports. Toutes les historiographies ici concernées ont diversifié leurs thèmes, ont porté leurs regards vers de nouvelles sources, sous l'influence de l'anthropologie, de la sociologie, de la théorie littéraire, ces derniers étant eux-mêmes en constant renouvellement. L'éclectisme pluraliste est de mise, avec parfois quelques travers pointés ici ou là : l'absence de fil directeur, une perte de clarté conceptuelle, un émiettement et une fragmentation des terrains de recherches. Mais d'une manière générale ces ouvertures sont vécues comme un enrichissement offrant une meilleure 
compréhension des sociétés. Effervescence et renouveau. Les "dix-neuviémistes" ont l'avenir devant eux.

Cependant, ce dossier spécialement consacré à l'histoire de l'Europe du XIX ${ }^{e}$ siècle ne s'arrête pas à ce constat optimiste. Il propose de réfléchir sur sa genèse, et au fil des articles on sent à quel point l'éclectisme actuel plus ou moins joyeux, c'est selon, ne revêt pas le même sens en fonction des pays concernés. En Allemagne, en Espagne et en Italie, dont les historiographies ont une tradition comparatiste, la crise des grands discours de la modernisation, porteurs de l'idée de trajectoires modèles et normales, a contribué à une certaine émancipation vis-à-vis d'une "légende noire" du XIX siècle. Sandrine Kott, Juan Pan-Montojo, et Pietro Causarano se rejoignent quand ils disent à quel point une certaine conception téléologique a pesé sur des historiographies préoccupé de Sonderweg, autrement dit d'un libéralisme politique tronqué, anormal et anomique, empêtré dans un archaïsme des structures sociales et économiques. De moins en moins de travaux désignent la dégénérescence des bourgeoisies de ces pays comme responsable. Au contraire, la spécificité du notable, l'individu banal et à part entière, les cultures nationales, les cultures de classe, permettent un comparatisme moins honteux, moins inquiet. À l'inverse, James Thompson et Michèle Riot-Sarcey montrent qu'en Grande-Bretagne et en France, pays porteurs de modèles et moins ouverts au comparatisme, l'abandon des grands paradigmes et des objectifs de globalisation a ouvert une période de doute et d'incrédulité. Les catégories du discours historien, que l'on pense à celle de "social" par exemple, ont été repensées. Surtout, elles ont été rapportées aux conditions idéologiques de leur apparition précisément au $\mathrm{XIX}^{e}$ siècle. L'auto-représentation des élites, les normes dominantes, la restauration des hiérarchies aux lendemains des secousses révolutionnaires, sont dorénavant mises au regard des résistances, des détournements, des expériences et des compréhensions perdues, vaincues ou oubliées. L'enracinement progressif de la démocrate représentative, le développement de l'industrie et de l'urbanisation, ne semblent plus avoir été seulement des facteurs d'unité. D'autres solidarités, d'autres identités sont dorénavant mises à jour. On voit grâce à ce numéro d'Histoire et Sociétés combien ces débats, qui nous sont maintenant familiers, gagnent à être replacés dans une démarche comparatiste. C'est le sens d'un l'appel à communication lancée par l'équipe de cette très entreprenante revue pour un colloque d'envergure sur ces changements historiographiques qui bouleversent les interprétations sur le XIX ${ }^{e}$ siècle. Il serait bon que d'une manière d'une autre La Revue d'histoire du XIX ${ }^{e}$ siècle apporte sa contribution à cet édifice, annonciateur de ce qui est devant nous. 